\title{
Accessible online neuroplasticity-targeted training for children with ADHD
}

\author{
Jyoti Mishra ${ }^{1,2^{*}}$, Michael M Merzenich ${ }^{2}$ and Rajesh Sagar ${ }^{3}$
}

\begin{abstract}
Childhood Attention Deficit Hyperactivity Disorder (ADHD) is a growing mental health concern worldwide. Effective, accessible and low-cost therapeutics for the disorder are urgently needed. Here we introduce a novel internet-based cognitive training intervention: Online Neuroplasticity-based Training for the Remediation of ADHD in Children (ONTRAC). The intervention is deployed in the home setting; it is customized to the cognitive capacities of each child and progressively improves performance in the specific neuro-cognitive domains deficient in ADHD. A feasibility trial of ONTRAC is being conducted in a resource limited clinical setting in New Delhi, India and is an exemplar of hi-tech global psychiatry.
\end{abstract}

Keywords: Attention Deficit Hyperactivity Disorder, ADHD, Cognitive training, Neuroplasticity, Neurotherapeutic, Global mental health

\section{Correspondence}

Nearly $10 \%$ of children worldwide are being diagnosed with ADHD [1-3]. With the new DSM-V diagnostic criteria [4] adopted around the world, childhood ADHD rates are further likely to increase, and the disorder is poised to become a global mental health epidemic. Given the immense socio-economic and healthcare burden posed by the disorder, developing effective and accessible treatments is an immediate need.

Stimulant medications remain the conventional first line of treatment in many countries, partly due to unavailability of any other reasonable treatment option [5-7]. However, research shows that while these medications improve on-task attention and provide respite in the short-term, significant behavioral impairments and poor academic performance persist over the long-term and medication side effects accumulate [8]. Further, in resource-limited global settings, there is poor access to affordable medications, mental health specialists and long-term care, and social stigma surrounds diagnosis and pharmacological treatment of mental disorders in many countries $[9,10]$. In general, parents worldwide prefer treatments for their children that are accessible,

\footnotetext{
* Correspondence: jyoti.mishra@ucsf.edu

'Department of Neurology, Physiology and Psychiatry, Sandler Neurosciences Center, University of California, San Francisco, CA 94158, USA

${ }^{2}$ Brain Plasticity Institute, PositScience, San Francisco, CA 94108, USA Full list of author information is available at the end of the article
}

affordable, sustainable within the family's lifestyle and those found to be effective in clinical trials. In this context, cognitive training $(\mathrm{CT})$ is emerging as a promising new alternative and/or medication-adjunct treatment option for ADHD [11,12].

The advantage of modern $\mathrm{CT}$ is that it is internetbased and hence accessible from any remote setting. Scientifically, we can now develop CT that is specifically targeted to the core neuropsychological and cognitive impairments observed in a neuropsychiatric disorder or clinical population [13-17]. Using principles that drive neuroplasticity [18], we have recently developed such a novel CT aimed at improving cognition in children with ADHD: Online Neuroplasticity-based Training for the Remediation of ADHD in Children (ONTRAC). ONTRAC incorporates technological advances that facilitate integration within clinical care: it is internet-deployed on secure servers so that children can conveniently access the training from any computer in their home setting; it automatically tracks compliance and performance progress in training session data uploads to the cloud, and it is scalable and sustainable as a single clinician can remotely monitor the training progress of hundreds of children simultaneously.

Scientifically, ONTRAC features cognitive personalization as the training challenges are adaptively modified in real-time based on the individual's current performance 
capabilities. Most importantly, ONTRAC is customdesigned to selectively target ADHD-specific deficits in five critical neuro-cognitive domains of alertness, sustained and selective attention, working memory, impulsive response control and suppression of distracting interference. No prior ADHD CT program has comprehensively targeted all of these cognitive domains; especially, the key deficits observed in suppression of distracting information have not been targeted.

ONTRAC is being currently evaluated in a recently initiated randomized controlled feasibility-efficacy trial in New Delhi, India [19]. All study procedures and written informed consents obtained from participating families were approved by the Institution Ethics Committee at the All India Institute of Medical Sciences, New Delhi (Approval \# IEC/NP-359/2011 \& RP-03/2012). This global setting, with limited specialized psychiatric care yet widespread internet-connectivity, is well suited for assessing the utility of ONTRAC to impact ADHD when access to clinical resources is sparse [20]. Adolescent children access and progress through training from their home setting performing 30 hours of CT over 6 months. An age and medication-status matched active control group engages in 30 hours of non-therapeutic video game play over the same time period. Training parameters such as content, duration and frequency have all been carefully titrated to maximize engagement, compliance and efficacy. Changes in ADHD symptoms and in underlying neuropsychological function are being measured in 3-monthly visits: pre-, mid-, post-training and in a 6-month followup.

Results pending, the ONTRAC trial illustrates in principle how modern technology and clinical neuroscience can be integrated for the development and evaluation of a 21st century personalized neurotherapeutic that may benefit many individuals with neuropsychiatric impairments in remote and resource-limited settings. We are aware that we may not achieve positive longterm real-life impacts in a first trial. Yet, the technology base of ONTRAC allows rapid iterative software development cycles. When rapid technology development is coupled with systematic and well-controlled clinical trial evaluations, it is envisaged that research efforts would ultimately converge onto an efficacious cognitive training program in the near future that has global positive and sustaining impact on ADHD in children.

\section{Abbreviations}

ADHD: Attention Deficit Hyperactivity Disorder; CT: Cognitive training; ONTRAC: Online Neuroplasticity-based Training for the Remediation of ADHD in Children.

\section{Competing interests}

$J M$ is a part-time scientist at the Brain Plasticity Institute, PositScience and MM is President and Founder of Brain Plasticity Institute, PositScience, a company that develops cognitive training software.

\section{Authors' contributions}

All authors contributed to the writing and approval of this letter.

\section{Acknowledgments}

This work was supported by the National Institute of Health 5R24TW00798805 subaward VUMC38412 (JM). We would like to thank Alankar Misra for his software development support for ONTRAC and Angela Joseph for her data collection efforts for the ONTRAC trial.

\section{Author details}

${ }^{1}$ Department of Neurology, Physiology and Psychiatry, Sandler Neurosciences Center, University of California, San Francisco, CA 94158, USA. ${ }^{2}$ Brain Plasticity Institute, PositScience, San Francisco, CA 94108, USA. ${ }^{3}$ Department of Psychiatry, All India Institute of Medical Sciences, New Delhi 110029, India.

Received: 22 October 2013 Accepted: 11 November 2013

Published: 14 November 2013

\section{References}

1. Froehlich TE, Lanphear BP, Epstein JN, Barbaresi WJ, Katusic SK, Kahn RS: Prevalence, recognition, and treatment of attention-deficit/hyperactivity disorder in a national sample of US children. Arch Pediatr Adolesc Med 2007, 161:857-864.

2. Perou R, Bitsko RH, Blumberg SJ, Pastor P, Ghandour RM, Gfroerer JC, Hedden SL, Crosby AE, Visser SN, Schieve LA, Parks SE, Hall JE, Brody D, Simile CM, Thompson WW, Baio J, Avenevoli S, Kogan MD, Huang LN: Mental health surveillance among children-United States, 2005-2011. MMWR Surveill Summ 2013, 62(Suppl 2):1-35.

3. Mukhopadhyay M, Misra S, Mitra T, Niyogi P: Attention deficit hyperactivity disorder. Indian J Pediatr 2003, 70:789-792.

4. Attention Deficit/ Hyperactivity Disorder. [http://www.dsm5.org/Documents/ ADHD\%20Fact\%20Sheet.pdf]

5. Spiller HA, Hays HL, Aleguas A: Overdose of drugs for attention-deficit hyperactivity disorder: clinical presentation, mechanisms of toxicity, and management. CNS Drugs 2013, 27:531-543.

6. Dopheide JA, Pliszka SR: Attention-deficit-hyperactivity disorder: an update. Pharmacotherapy 2009, 29:656-679.

7. Remschmidt H: Global consensus on ADHD/HKD. Eur Child Adolesc Psychiatry 2005, 14:127-137.

8. Molina BSG, Hinshaw SP, Swanson JM, Arnold LE, Vitiello B, Jensen PS, Epstein JN, Hoza B, Hechtman L, Abikoff HB, Elliott GR, Greenhill LL, Newcorn JH, Wells KC, Wigal T, Gibbons RD, Hur K, Houck PR: The MTA at 8 years: prospective follow-up of children treated for combined-type ADHD in a multisite study. J Am Acad Child Adolesc Psychiatry 2009, 48:484-500.

9. Saxena S, Thornicroft G, Knapp M, Whiteford H: Resources for mental health: scarcity, inequity, and inefficiency. Lancet 2007, 370:878-889.

10. Wilcox CE, Washburn R, Patel V: Seeking help for attention deficit hyperactivity disorder in developing countries: a study of parental explanatory models in Goa, India. Soc Sci Med 2007, 64:1600-1610.

11. Rutledge KJ, van den Bos W, McClure SM, Schweitzer JB: Training cognition in ADHD: current findings, borrowed concepts, and future directions. Neurotherapeutics 2012, 9:542-558.

12. Klingberg T: Training and plasticity of working memory. Trends Cogn Sci 2010, 14:317-324.

13. Tallal P, Miller SL, Bedi G, Byma G, Wang X, Nagarajan SS, Schreiner C, Jenkins WM, Merzenich MM: Language comprehension in languagelearning impaired children improved with acoustically modified speech. Science 1996, 271:81-84.

14. Fisher M, Holland C, Merzenich MM, Vinogradov S: Using neuroplasticitybased auditory training to improve verbal memory in schizophrenia. Am J Psychiatry 2009, 166:805-811.

15. Smith GE, Housen P, Yaffe K, Ruff R, Kennison RF, Mahncke HW, Zelinski EM: A cognitive training program based on principles of brain plasticity: results from the Improvement in Memory with Plasticity-based Adaptive Cognitive Training (IMPACT) study. J Am Geriatr Soc 2009, 57:594-603.

16. Anguera JA, Boccanfuso J, Rintoul JL, Al-Hashimi O, Faraji F, Janowich J, Kong E, Larraburo Y, Rolle C, Johnston E, Gazzaley A: Video game training enhances cognitive control in older adults. Nature 2013, 501:97-101.

17. Mishra J, Anguera J, Ziegler D, Gazzaley A: A Cognitive Framework for Understanding and Improving Interference Resolution in the Brain. In 
Chang Brains - Appl Brain Plast to Adv Recover Hum Abil. Edited by Merzenich M, Nahum M, van Vleet T. Elsevier; 2014. in press.

18. Merzenich MM, DeCharms RC: Neural representations, experience, and change. In Mind-brain Contin Sens Process. Edited by Llinás RR, Churchland P. Cambridge, MA, US: The MIT Press; 1996:61-81.

19. Online Neuroplasticity Training for Remediation of ADHD in Adolescent Children (ONTRAC). ClinicalTrials.gov [http://clinicaltrials.gov/ct2/show/ NCT01772485]

20. Patel V, Araya R, Chatterjee S, Chisholm D, Cohen A, de Silva M, Hosman C, McGuire H, Rojas G, van Ommeren M: Treatment and prevention of mental disorders in low-income and middle-income countries. Lancet 2007, 370:991-1005.

doi:10.1186/1753-2000-7-38

Cite this article as: Mishra et al: Accessible online neuroplasticitytargeted training for children with ADHD. Child and Adolescent Psychiatry and Mental Health 2013 7:38.

\section{Submit your next manuscript to BioMed Central and take full advantage of:}

- Convenient online submission

- Thorough peer review

- No space constraints or color figure charges

- Immediate publication on acceptance

- Inclusion in PubMed, CAS, Scopus and Google Scholar

- Research which is freely available for redistribution 